\title{
ANÁLISE DAS DISCIPLINAS DE GERONTOLOGIA NOS CURRÍCULOS DOS CURSOS DA SAÚDE NO RIO GRANDE DO SUL
}

Guilherme Briczinski de Souza; Universidade Federal de Ciências da Saúde de Porto Alegre; gbriczinski@gmail.com

Fernanda Górski; Universidade Federal de Ciências da Saúde de Porto Alegre; fergorski@gmail.com Juliane Pinto Lucero; Universidade Federal de Ciências da Saúde de Porto Alegre; julianeplucero@gmail.com Julyhe Nunes Paulin; Universidade Federal de Ciências da Saúde de Porto Alegre; paulinjulyhe@gmail.com

Eduardo Garcia; Universidade Federal de Ciências da Saúde de Porto Alegre; eduardosgarcia@terra.com

\section{RESUMO}

Introdução: A população idosa está em crescimento devido ao aumento da expectativa de vida. Portanto, por consequência, o atendimento de saúde terá que adaptar-se para a futura demanda desta faixa etária, além de aumentar o número de profissionais habilitados para atendê-los. Objetivo: Identificar a presença de disciplinas obrigatórias em cursos da área da saúde que abordam o paciente idoso. Metodologia: Estudo transversal, no qual foram analisados os currículos dos cursos de Educação Física, Enfermagem, Fisioterapia, Fonoaudiologia, Nutrição, Odontologia e Psicologia em 36 universidades no Rio Grande do Sul. Foram pesquisadas disciplinas ligadas a gerontologia e/ou saúde do idoso. Foram excluídos aqueles com cursos na modalidade a distância, tecnológicos e licenciaturas, disciplinas eletivas/optativas e currículos anteriores ao ano letivo de 2019. Resultados: Foram encontrados 30 cursos de Psicologia, 28 de Enfermagem, 27 de Fisioterapia, 25 de Educação Física, 22 de Nutrição, 18 de Odontologia e 7 de Fonoaudiologia, dos quais apenas 82,1\% dos cursos de Enfermagem e 62,9\% dos de Fisioterapia tiveram disciplinas obrigatórias ligadas a saúde do idoso. O curso de Nutrição teve metade dos currículos (50\%) com alguma disciplina na área da gerontologia, enquanto a Fonoaudiologia (42,8\%), a Psicologia (33,3\%), a Educação Física (32\%) e a Odontologia (5,5\%) ficaram com menos da metade das disciplinas obrigatórias. Conclusão: Perante os dados apresentados a maioria dos cursos da área da saúde não apresentam as disciplinas sobre a saúde do paciente idoso de modo obrigatório no currículo.

Palavras-chave: Currículo; Ensino; Saúde do Idoso. 